\title{
Factors Effective on Knowledge Management in Service-Oriented Organizations (Senior Managers Opinion Using Analytical Hierarchy Process (AHP)
}

\author{
Mansoor Ezzati Jivan \\ Faculty member of Sama Institute, Allameh Tabatabee University \\ 2th Unit, No. 14, 6th St., Mehran Ave, Kashani Highway, Ariashahr, Tehran, Iran \\ E-mail:m.ezzati@gmail.com \\ Maryam Zarandi \\ Faculty member of Sama Institute, Allameh Tabatabee University \\ 2th Unit, No. 14, 6th St. , Mehran Ave, Kashani Highway, Ariashahr, Tehran, Iran \\ Tel: 98-912-698-0426Ｅ-mail: m.zarandi2009z@yahoo.com
}

Received: December 10, 2011

Accepted: January 17, 2012

Published: March 1, 2012

doi:10.5539/ijbm.v7n5p150

URL: http://dx.doi.org/10.5539/ijbm.v7n5p150

\begin{abstract}
Today, knowledge is considered as an important competitive advantage for organizations. Hence, senior managers have conceived its essential role to achieve a competitive advantage and engage in strategic goals of organizations. They consider knowledge management implementation as a crucial factor to survive in a competitive environment. Through senior managers' view based on Analytic Hierarchy Process (AHP), the author have aimed at setting priorities for factors effecting on knowledge management implementation in service-based organization. To do that, a questionnaire survey about the priority of factors effecting on Hansen et al(Note 1) (2004) knowledge management strategy was conducted from 20 senior managers of service-based organizations based on Analytic Hierarchy Process (AHP). Results showed that organizational culture and Individual employment relations jointly engaging in knowledge sharing, and also individual networking were respectively the first three priorities; and creating suitable infrastructures for information technology and proper information and knowledge encoding are the last two priorities. In managers' view, these factors can effect on knowledge management implementation in organizations.
\end{abstract}

Keywords: Knowledge management, Service-oriented organization, AHP

\section{Introduction}

Each organization is a vast source of knowledge which often a part of it remains hidden, however, the truth is, due to lack of clear images about how to implement this kind of knowledge, the organizations are unable to ideally and favorably design and implement the knowledge management system. According to authors, organizations should operate efficiently in knowledge function in order to survive in complex and dynamic environments. Among these, the service-oriented organizations, due to their processing nature, require more information on people's understanding and knowledge level. Understanding the importance of knowledge management, such organizations are more tended towards applying this system. These organizations have found out that in terms of the international competition dominant on industry and services areas, on time and quick access to valid knowledge is considered as a competitive advantage for the organization that the best way to create this advantage is to implement comprehensive knowledge management in organizations.

Thus, the organizations would be successful if they use different management approaches and novel technologies in order to utilize the opportunities, where knowledge management is a sample of applying such approaches. Although knowledge is crucial as a source for organizations' survival and the organizations' success condition in world trading is to obtain deep knowledge in all levels, it should be noted that knowledge management has different meanings for every organization (Kruger, 2010). Effective knowledge management by focusing on 
solutions, which include the entire organizational, human resources, and technology system, is considered as one of the best tools for organizations' promotion (Asadzadeh, 2006). For knowledge management being successful in an organization, providing intellectual and cultural backgrounds, knowledge focuses, as well as modern technologies are crucial. One of the factors which have the most contribution this, is concentrating on work processes (Moghimi, 2005). By emerging the knowledge management as an effective tool, products called knowledge management systems for organizations came into existence (Jafari Moghadam, 2002). In the knowledge management perspective, a large portion of changes in business processes are derived from changing production capabilities and knowledge management of working processes (Akbarpoor Shirazi et al., 2006). For designing an effective knowledge management and or promoting its level in a service-oriented organization using information technology, first it is necessary to obtain a complete understanding on knowledge and knowledge management nature and importance in a organization, and beds and fields of knowledge management success and how to establishing interactions and balance among these factors should be specifically considered by identifying the components and their functions and in order to achieve strategic advantages from implementing the knowledge management in organizations. In this paper, the senior managers' opinions of 10 service providing organizations, such as insurance agency, bank, and educational and research institutes, were used in order to prioritize the effective factors on implementing knowledge management in organizations.

\section{Knowledge and Knowledge Management in Service-oriented Organizations}

Knowledge management (KM) could provide a consistent competitive advantage for service-oriented organizations since knowledge sources are complex from social perception perspective and it is also hard to imitate (Firestone, 2008). Since in service-oriented organizations the output is not a tangible product, knowledge management should have the value creation capability from visible assets and moral capital of the organization and converting it to intangible services and presenting it to society.

Indeed, it is the obvious and systematic knowledge management and its related creating, collecting, organizing, and application processes which provide a deliberate knowledge creation, knowledge validation, knowledge provision, knowledge distribution and its application in providing services (Nonaka EDS, 2008). The knowledge management is the organization's capability in using staff's empirical capital and individual knowledge on one hand, and on the other hand the collective knowledge in order to achieve goals through knowledge creation processes, knowledge sharing, and using it by means of technology. Based on these theoretical principles, the knowledge management includes developing, implementing and maintaining technical and organizational infrastructures as a field and necessity to distribute knowledge and to choose special technologies in service-oriented organizations. The knowledge management in such organizations is the developed concept of information management systems from the technical perspective, which rely on management of data, current knowledge, and internal relationships between information objects (Ron Sanchez, 2005).

According to Gupta, knowledge management $(\mathrm{KM})$ in organizations is a process which helps an organization to choose, organize, and distribute the most important skills and information needed and essential for performing its activities and to convey them (Gupta, 2010). This definition is practical in service-oriented organizations since in this kind of organizations, it is possible to provide services with higher quality through properly using the employees' skills and knowledge. KM in such organizations has higher importance. This could be due to providing human services instead of tangible commodities and products to society and people.

\section{KM Structure in Service-oriented Organizations}

The KM structure in service-oriented organizations has slight differences with production organizations. As Watson believes, the KM structure could be divided into following groups (Watson, 2003):

\subsection{Leadership and management}

Deals with environmental, strategic, and decision-making activities at the company level, which includes valuation, determining goals, knowledge requirements, knowledge sources, prioritizing, and allocation of resources and organizational knowledge capital. The service-oriented organizations despite being different from production organizations in terms of strategy and purposes, but act at more efficient level of axial wisdom from the aspect of context, management, and leadership in applying knowledge.

\subsection{Organization}

Deals with operational aspects of knowledge capitals, which includes tasks, processes, formal and informal structures, control indices and measurements, process improvement, and reengineering of processes. In this part of the structure, the service-oriented organizations also design, analyze, and improve production process and knowledge transfer, as it is in other organizations. The only difference is in determining the knowledge process 
type since in such organizations; knowledge has more importance in the organization's output quality (provided services quality).

\subsection{Technology}

This part deals with different information technologies, specially for supporting and empowering KM strategies and its practice. It should be noted that in all organization such as service organizations, the type of applied technology and infrastructure for implementing KM depends on the organization's main policies and strategies.

\subsection{Learning}

In Watson's classification, this group deals with the organization's behavioral aspects and social engineering. In fact, this aspect focuses on principles and practices which ensure the knowledge sharing and increased cooperation among people, and its concentration is on identification and application of characteristics needed for organizational learning. One of the ultimate objectives of each organization is to become a learner organization. A learner organization is an organization which facilitate learning for all an constantly expose itself to effective evolution and change (Peddler, 1989). Marquardt has expanded this definition to an organization which strongly and collectively acquires learning and constantly changes individuals to better collect, manage, and use knowledge in achieving success (Marquardt, 2002). It seems that latter definition is in more conformity with service-oriented organizations, since in these organizations a knowledge evolution based on wisdom-oriented strategies is inevitable for being successful in delivering services to society. In characteristics of such organizations, learning plays a fundamental role in knowledge acquisition.

\section{Knowledge Levels in Implementing KM}

As mentioned before, knowledge is placed in different classes for progressing an organization's strategic plans. In fact, knowledge has different levels within an organization which could be presented in two major levels with a similar approach in service-oriented organizations:

\subsection{Knowledge owner}

This includes individual, group, and different organization levels. Unlike individual knowledge, the group knowledge includes a combined knowledge like a team, which forms beyond the sum of each team member's knowledge, since different types of knowledge provided by different members lead to development of a new knowledge source. The organizational levels are themselves a specific indicator of group knowledge which defines the knowledge formed by all the members of an organization. The organizational knowledge encompasses all specialized skills and capabilities of an organization and every different activity which takes places within it.

\subsection{Knowledge extent}

This consists of two horizontal and vertical aspects. The general hierarchical differences if knowledge could be for example stated with the differences between personnel needs and mangers needs of a plant for knowledge. Depending on the topic's type from the horizontal flow perspective, for example, the quality management and human resources management could be in the executive levels and R\&D, product designing, and product development could be in the operational level (Jahanian, 2005).

\section{Studies and Researches Performed on Knowledge Management and Transfer}

To date, several researches are identified as key factors in knowledge management and transfer success. These factors are different because different authors have had different approach and perspective on them, and each has investigated them from a special aspect. The following table presents a brief description of researches been carried out up to date around key factors in knowledge management and transfer success.

Reviewing the studies carried out, four general models were obtained for evaluating the KM implementation. These four models are:

a) The EC model of KM: in this model, the KM success is investigated in eight components which are: KM strategy, human and social factors, organizational structure and supporters, KM processes, leadership, KM scaling and application (Ibermatica, 2002).

b) KM evaluation tool model: evaluating the organization using this model is, in fact, measuring the organization's system maturity. Based on this, five organization maturity levels are considered, where the answers to the proposed questions are "yes" or "no", and indicates the organization's KM maturity level which ranges between level one too level five. 
c) Knowledge-network evaluation model: this model evaluates in these three dimensions: knowledge assets (human, organizational, and instrumental), KM infrastructure (strategic, processes, and structure), and knowledge network levels (including individuals and teams).

d) Knowledge-everyone evaluation model: this model evaluates KM success based on ten main axes which are referred as success key factors. These ten axes are: leadership, culture and structure, processes, apparent knowledge, hidden knowledge, knowledge centers and focuses, people (skills), reinforcing the knowledge market, scaling knowledge, technological infrastructure (W. Horton, 2001).

\subsection{Research's theoretical framework}

In this study, by investigating and comparing these four models, and considering the features of each, the Hansen et al. model was used which is included in the knowledge-network evaluation model set, since it is being localized in Iranian service-oriented organizations. Hansen et al. implemented KM strategy through coding and personalization. In this model two main strategy aspects of organization are introduced as: 1. Information and knowledge coding, 2. Knowledge personalization in organization.

The HNT model is a proper model for implementing the KM strategy in an organization, since the type of adopted strategy depends on business nature and the organization must take an efficient and effective combined knowledge strategy. That is, the organization must pursue the individual-document relationship strategy as an "outrider" strategy and personalization strategy as a supporter (Hansen, 2004). As shown in the model, the person-person strategy consists of organizational culture, networking, and interpersonal relationships, and the person-document strategy is related to IT infrastructure and coding, which are investigated in this research.

\section{Research Methodology}

The current study is an applied research and its data collection method is documental and field, where for theoretical principles, the library research method, and for data collection, the questionnaires were used. In order to determine the questionnaire validity, the university professors and authors opinions were used, and the questionnaire was revised and modified based on the received suggested opinions. This questionnaire has two parts: the first part of the questionnaire is related to data collection for applying the AHP model, and the second part is associated to the factors prioritizing from the managers' point of view. This questionnaire was distributed among 20 managers of service providing organizations. The model's flexibility and using the AHP method enables to give different weights to the relative indices based on need and application of this tool in various business and processes. Since the AHP technique is based on group decision-making, therefore it is necessary to turn the collected data from questionnaires into compilation.

\subsection{Data analysis}

For analysis of raw data collected from questionnaires, first the paired comparison matrices for each answerer in each case should be combined in term of a compiled matrix. The geometric mean was used for compilation which is one of the best methods for combining the comparison tables of group members. Whenever the opinions have equal significance degree, the following equation could be used for calculating the geometric mean (Sakaran, 2001):

$$
\bar{a} \cdot \mathrm{ij}=\left(\begin{array}{cc}
N \\
\pi & a^{k} \\
k=1
\end{array}\right)^{\frac{1}{N}}
$$

If the members' vote has different specific priority coefficient, the following equation could be applied:

$$
\bar{\alpha} \mathrm{ij}=\left(\begin{array}{c}
N \\
\pi \quad a^{(w k)} \\
k=1
\end{array}\right) \bar{\Sigma}
$$

After compiling the paired matrices, the paired comparisons matrices would be as follows:

Next, in order to extract the priorities, first the figures in comparison tables should be normalized and then determining the average for each row, the weight of each factor is obtained. Finally, after calculating the adaptability rate of paired comparison matrices, the priority of effective factors in this technique are determined.

$$
\text { Normal } r_{i j}=\frac{\bar{a}_{i j}}{\sum_{i=1}^{m} \bar{a}_{i j}}
$$


Next, the adaptability rate of paired comparison compiled matrices was calculated so that the comparisons adaptability could be determined. That is, to what extent one could trust the priorities obtained from group members. Empirically, it is shown that, if the compatibility rate (CR) is lower than 0.1, then the comparisons adaptability could be confirmed; otherwise the comparisons should be repeated. In order to calculate the adaptability rate, first the weighted sum vector (WSV) is calculated using WSV $=\mathrm{A} . \mathrm{W}$.

$$
\begin{gathered}
\text { WSV }=\left(\begin{array}{ccc}
1 & 6.87 & 6.64 \\
0.145 & 1 & 5.48 \\
0.150 & 0.182 & 1
\end{array}\right)\left(\begin{array}{l}
0.709 \\
0.217 \\
0.074
\end{array}\right)=\left(\begin{array}{l}
2.671 \\
0.708 \\
0.219
\end{array}\right) \\
\text { WSV }=\left(\begin{array}{cc}
1 & 0.303 \\
3.30 & 1
\end{array}\right)\left(\begin{array}{l}
0.276 \\
0.763
\end{array}\right)=\left(\begin{array}{l}
0.507 \\
1.673
\end{array}\right)
\end{gathered}
$$

The second step is to calculate the compatibility vector (CV) based on:

$$
\begin{gathered}
\mathrm{CV}=\frac{\mathrm{wsv}}{w} . \\
\mathrm{CV}_{1}=\left(\begin{array}{l}
1.84 \\
2.19
\end{array}\right) \quad \quad \mathrm{CV}_{2}=\left(\begin{array}{l}
3.767 \\
3.262 \\
3.042
\end{array}\right)
\end{gathered}
$$

The third step is to calculate the specific amounts which are the CV averages.

$$
\lambda_{\max } \frac{1}{n}\left(\sum_{i=1}^{n}, c v\right)
$$

Fourth step is to calculate the compatibility index (CI) using $\quad C l=\frac{\lambda_{\max }-n}{n}$ and the compatibility rate is calculate during the last step by $\quad C R=\frac{C I}{R I}$, which for individual with documents and information effective factor and person with person effective factor is 0.013 and 0.025 , respectively. This shows that factors priority matrices are trustworthy from managers' points of view. The calculation results related to compatibility rate and matrix are presented in the following table.

The results obtained showed that all matrices have good CR. Using the SMART method and factors prioritizing based on Hansen et al. idea, the weight for each factor was calculated.

Organizational culture $>$ interpersonal networking $>$ personal relationships $>$ information coding $>I T$ infrastructures

According to the obtained weights, sorting the final weight options, the factor effective on implementing KM in service-oriented organizations were prioritized from managers' points of view using the AHP technique.

\section{Conclusions and Suggestions}

Knowledge by itself is not an important source for any organization since knowledge is not for knowledge, but knowledge is for operation and improving the effective performance. On the other hand, all organizations are facing KM objectively or subjectively. In this paper, the factor effective on implementing $\mathrm{KM}$ in service-oriented organizations was prioritized from top managers' opinions using the AHP technique. To do so, the opinions of 20 top managers of service-oriented organizations, such as insurance agency, bank, and educational and research organizations, were investigated. According to the performed analysis using the AHP technique, it is expected that combing 20-80 HNT models, by balanced concentration of coding and personalization strategy in implementing KM in an organization, respectively, these two are converging. To the extent that the personalization and knowledge coding strategies have reached their highest limit and have led to more efficiency and creating a learner organization. Indeed, choosing the strategy type depends on business nature and organization's economic policy, but according to the obtained results from this research, it could be 
Organizations might recognize the need for implementing the organization's KM over time which depends on the organization's knowledge exchange and culture, since by properly identifying the organization's culture, management would be able to organize short-term, medium-term, and long-term plans for implementing KM, and to increase the success and survival coefficient probability. The second factor is the personal relationship of personnel in interaction with each other in knowledge sharing. An organization which puts its knowledge strategy based on forming workgroups and developing human resources capabilities would be successful, so that the employees would contribute in accelerating the $\mathrm{KM}$ implementation through string interpersonal relationships. One of the approaches for improving the personal relationships in organizations, which is also recommended in most studies, is creating cross-functional teams in organization. Specially, in service-oriented organizations, creating such specialized teams and groups leads to integrity and strengthening the employees' relationships.

After personal relationships, the interpersonal networking through creating interfacing groups between staffs workgroup is also important. That is, organization units with different functions could participate in achieving common goals and promoting interpersonal knowledge. In the end, creating proper IT infrastructures and using new technologies for both updating information and facilitating knowledge sharing in different organization's levels, although brings major expenses for organization, could be effective in implementing KM, because in managers opinion this expense is considered as a capital in long-term. Information correct coding could be effective in implementing KM in service-oriented organizations. In order to decrease any interference and disturbance in information coding, especially in service-oriented organizations, placing control stations (CS) in plans and information systems is recommended to identify any error in information coding and move towards improving implementing KM.

\section{References}

A. Anvari Rostami \& B. Shaha'e. (2009). KM and learner organization: an analysis on knowledge documentation and experiment role. IT management $J$, 33(4), 233-245.

Asadzadeh, M. Jalalian. (2004). Knowledge management paper. 76(7), 55-59. [Online] Available: http://www.Iranian Health Information Management Students.

C.J. (Neels) Kruger, \& Roy D. Johnson. (2010). Information management as an enabler of knowledge management maturity: A South African perspective. (3rd ed.), (Chapter 4).

Ch. Valmohammadi. (2009). Determining and prioritizing the major factors in successful implementation of KM in national small and medium organizations. Management seasonal, 6(16).887-893.

Correia AM, \& Sarmento. (2003). Knowledge management: key competences and skills for innovation and competitiveness, the technology and HRM conference on the dual interaction between technology and human resource. France; (Chapter 8).

Firestone JM, \& McElroy MW. (2008). Key issues in the new knowledge management. Trans. Jafarnejad A, Safiri KH. Tehran: Entesharate Moaseseye Ketab Mehraban. Iran: Samt. (Chapter 1).

G. Probst, S. Raub, \& K. Romhardt. (2007). Manging knowledge: building blocks for success. Translated by H. Yarigar Ravesh. Moalef publications, (Chapter 3).

Gupta A., \& McDaniel J. (2010). Creating competitive advantage by effectively Managing Knowledge: a framework for Knowledge management. Knowledge management practice, 66(58), 324-329. [Online] Available: http://www.tlaince.com/ article39.htm

Hall R, \& Andriani P. (2002). Managing knowledge for innovation in: Long Range Planning. (pp. 28-30). New York: E-Publishing Inc.

IAT; IAO, BIBA, Ibérmatica. (2002). KM assessment model and tool. European KM Forum, (pp. 495-508). Japan: E-Publishing Inc.

Kh. Jahanian. (2005). KM: the heuristic process model. Pishgaman Fanavari Andisheh, 7(88).39-44.

M. Akbarpour S., I. Mahdavi, \& H. Soori. (2006). The organization's competitive advantage in reengineering compiled model and KM from balanced evaluation point of view. $4^{\text {th }}$ international management conference, 56(3), 33-39.

M. Allameh, S. Hosseinsadat \& A. Khadem. (2006). The effect of KM on organization sustainable innovation. Evolution management conference. Isfahan.Iran. 
M. Ezzati, M. A. Seyyed Naghavi. (2009). Entrepreneurship principles. Institute of labor and social security, (2th end). Iranian Center of Entrepreneurship, (Chapter 2).

Marquardt, M. (2002). Building the learning organization. McGraw Hill, New York, YN. ( Chapter 3).

Moghimi. (2005). Designing a software system for modeling the work processes based on knowledge management. Msc thesis. Industrial engineering. Amirkabir University of technology, 900(54), 56-63.

Nonaka EDS. (2008). The knowledge creating company. Harvard business review, 70 (69), $96-104$.

O. Sakaran. (2001). Research methods in management. Translated by M. Saebi and M. Shirazi. Tehran, governmental management education center, 98(544), 90-103.

Peddler, M, Boydell, T and Burgoyne, J. (1989). Towards the learning company. Management Education and Development, 20(1), 1-8.

Rens Scheepers, Krishna Venkitachalam, Martin R. Gibbs. (2004). Knowledge strategy in organizations: refining the model of Hansen. Journal of knowledge management, 13(7), 444-452.

Ron Sanchez. (2005). Knowledge Management and Organizational Learning. The technology and HRM conference on the dual interaction between technology and human resource, 14(12), 19-21. [Online] Available: http://ideas.repec.org/p/hhb/lufewp/2005_003.html

S. Jafari Moghadam. (2002). Organizational KM. Organizational KM, 23(769), 21-25.

S. Nouri, M. Jafari, M. Fathian, \& M. Ibrahimi. (2007). The role of KM in developing innovation in $R \& D$ centers. Nashr: Iranian. (Chapter 3).

Shu-hsien Liaoa, Wu-Chen Feib, \& Chih-Tang Liub. (2008). Relationships between knowledge inertia, organizational learning and organization innovation. The State University of New Jersey-Newark, 69-96.

W. Horton. (2001). "Knowledge Management”, William Horton consulting, Inc, Harvard business review, 69(9), 22-34. [Online] http://courses.jonesinternational.edu/private/jiu/media/pdf/edu622/edu622_KMT_01.pdf

Available:

Note

Note 1. Hansen, Nohria and Tierney (HNT).

Table 1. Key factors in knowledge management and transfer success from authors' points of view

\begin{tabular}{|c|c|c|}
\hline No. & Author & KM components \\
\hline 1 & $\begin{array}{l}\text { Davenport \& Prosac } \\
(1998)\end{array}$ & $\begin{array}{l}\text { Technology, knowledge creation, knowledge transfer, e-repositories of } \\
\text { knowledge, education, culture and leadership, trust }\end{array}$ \\
\hline 2 & Mary (1998) & Availability, correctness, being on-time \\
\hline 3 & Tressler (1998) & $\begin{array}{l}\text { Management commitment, encouraging for knowledge distribution, } \\
\text { culture, technology, education and learning }\end{array}$ \\
\hline 4 & Finran (1999) & Proper culture, knowledge and information creation and distribution \\
\hline 5 & Libuwitz (1999) & $\begin{array}{l}\text { KM strategy, top mangement support, encouraging personnel for } \\
\text { knowledge distribution, knowledge repository and technology }\end{array}$ \\
\hline 6 & Matasku (1999) & $\begin{array}{l}\text { Knowledge groups, supervising knowledge content, structural and } \\
\text { technologic supports, rehabilitation of knowledge creation and } \\
\text { distribution processes }\end{array}$ \\
\hline 7 & Bassy (2000) & Learning, distribution, implementing and using knowledge \\
\hline 8 & Choy (2000) & $\begin{array}{l}\text { Education, participation and empowering personnel, team-making, top } \\
\text { management support, knowledge structure, organizational constraints }\end{array}$ \\
\hline 9 & Skirm \& Omiden & $\begin{array}{l}\text { Having a necessitating outlook, knowledge leadership, knowledge } \\
\text { distribution culture, intelligent learning, technological infrastructure }\end{array}$ \\
\hline 10 & Hansen et al. & $\begin{array}{l}\text { People, technology and knowledge facilitating culture (1. Information and } \\
\text { knowledge coding, 2. Personalizing knowledge) }\end{array}$ \\
\hline 11 & Andereas Ridge (2005) & Organizational culture, organizational structure, and IT \\
\hline 12 & Hong and Huang (2005) & $\begin{array}{l}\text { Knowledge structure, organizational culture, IT, personnel participation } \\
\text { and education, leadership, learner organization, sources control, } \\
\text { performance evaluation, team-making }\end{array}$ \\
\hline
\end{tabular}


Table 2. The paired comparison compiled matrix of individual with documents and information factor

\begin{tabular}{|l|c|c|}
\hline Factors in implementing KM & IT infrastructure & Information coding \\
\hline IT infrastructure & 1 & 0.303 \\
\hline Coding & 3.30 & 1 \\
\hline
\end{tabular}

Table 3. The paired comparison compiled matrix of person with person factor

\begin{tabular}{|l|c|c|c|}
\hline Factors in implementing KM & $\begin{array}{c}\text { Organizational } \\
\text { culture }\end{array}$ & $\begin{array}{c}\text { Personal } \\
\text { relationships }\end{array}$ & $\begin{array}{c}\text { Interpersonal } \\
\text { networking }\end{array}$ \\
\hline Personal relationships & 6.64 & 6.87 & 1 \\
\hline Organizational culture & 5.48 & 1 & 0.145 \\
\hline Interpersonal networking & 1 & 0.182 & 0.150 \\
\hline
\end{tabular}

Table 4. The normalized matrix of individual with document and information effective factors

\begin{tabular}{|l|c|c|c|}
\hline Factors in implementing KM & IT infrastructures & Information coding & Row average \\
\hline IT infrastructures & $1 / 4.3$ & $0.303 / 1.303$ & 0.238 \\
\hline Information coding & $3.3 / 4.3$ & $1 / 0.303$ & 0.762 \\
\hline
\end{tabular}

Table 5. The normalized matrix of person with person effective factors

\begin{tabular}{|l|c|c|c|c|}
\hline $\begin{array}{l}\text { Factors in } \\
\text { implementing KM }\end{array}$ & $\begin{array}{c}\text { Organizational } \\
\text { culture }\end{array}$ & $\begin{array}{c}\text { Personal } \\
\text { relationships }\end{array}$ & $\begin{array}{c}\text { Interpersonal } \\
\text { networking }\end{array}$ & Row average \\
\hline Organizational culture & 0.709 & $6.64 / 13.12$ & $6.87 / 8.052$ & $1 / 1.3$ \\
\hline Personal relationships & 0.217 & $5.48 / 13.12$ & $1 / 8.052$ & $0.145 / 1.3$ \\
\hline $\begin{array}{l}\text { Interpersonal } \\
\text { networking }\end{array}$ & 0.074 & $1 / 13.12$ & $0.182 / 8.052$ & $0.150 / 1.3$ \\
\hline
\end{tabular}

Table 6 . The weighted sum vector and compatibility vector

\begin{tabular}{|l|c|c|}
\hline Facors in implementing KM & WSV & CV \\
\hline Organizational culture & 3.767 & 2.671 \\
\hline Personal relationships & 3.262 & 0.7080 \\
\hline Interpersonal networking & 3.042 & 0.219 \\
\hline IT infrastructures & 1.84 & 0.507 \\
\hline Information coding & 2.19 & 1.673 \\
\hline
\end{tabular}

Table 7. The priority matrix of effective factors on implementing KM

\begin{tabular}{|c|c|c|}
\hline Factors in implementing KM & $\mathrm{W}_{\mathrm{HNT}}$ & $\mathrm{W}_{\mathrm{H}}$ \\
\hline Organizational culture & 0.42 & 0.309 \\
\hline Personal relationships & 0.16 & 0.257 \\
\hline Interpersonal networking & 0.26 & 0.216 \\
\hline IT infrastructures & 0.04 & 0.121 \\
\hline Information coding & 0.09 & 0.097 \\
\hline
\end{tabular}




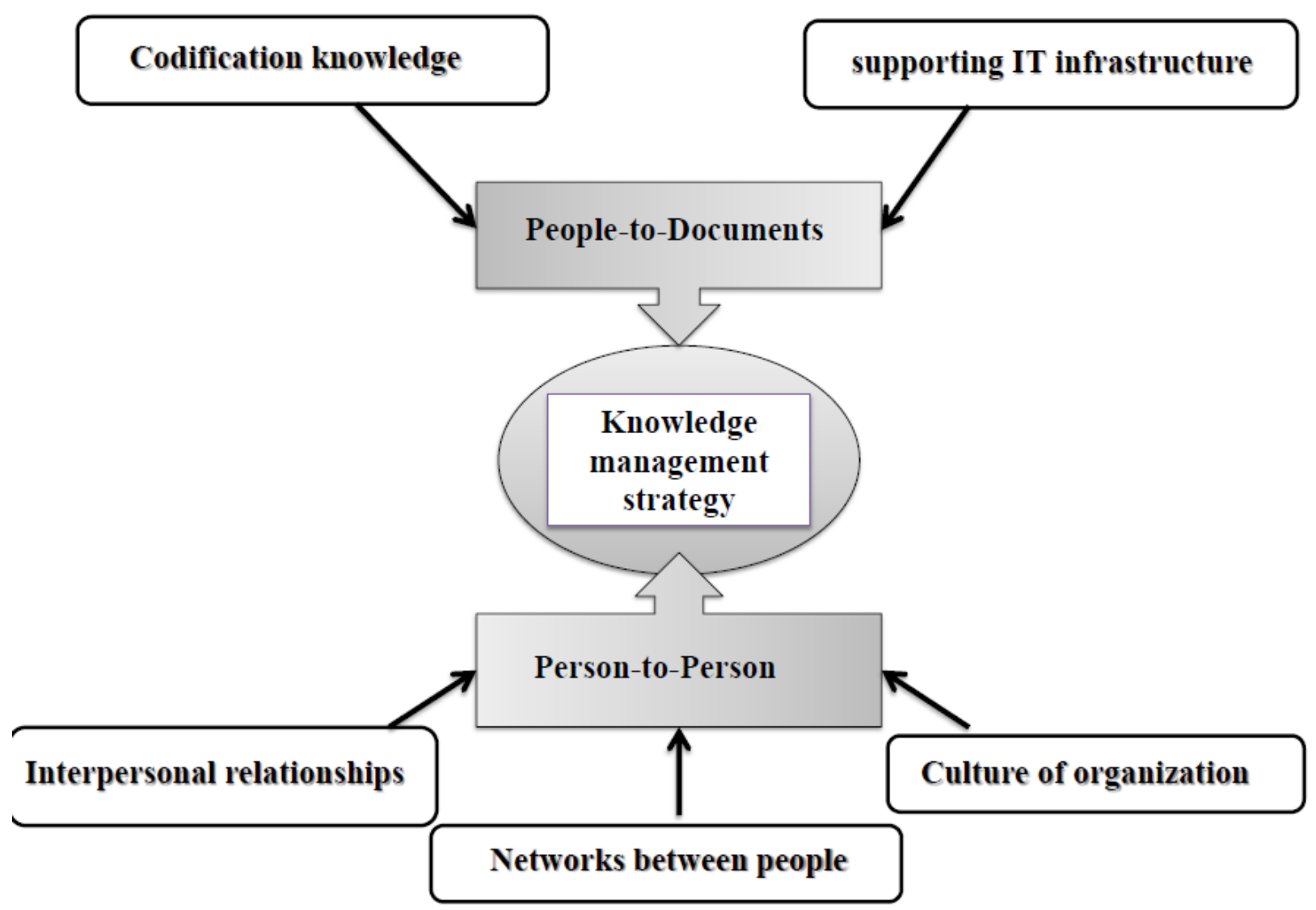

Figure 1. Model of research

Reference: Knowledge strategy in organizations: refining the model of Hansen, Nohria and Tierney, Rens Scheepers*, Krishna Venkitachalam, Martin R. Gibbs 2004. 